\title{
Comparative Study on the Evaluation of Wind Load on Buildings Using Computational Fluid Dynamics and IS: 875(Part-3)
}

\author{
J. Ashok ${ }^{1}$, Shirlin Charles ${ }^{2}$ and C. Umarani ${ }^{3}$ \\ ${ }^{1} \mathrm{PG}$ Student, ${ }^{2}$ Research scholar, ${ }^{3}$ Professor \\ Department of Civil Engineering, College of Engineering, Anna University, Chennai, Tamil Nadu, India \\ E-Mail:umarani@annauniv.edu
}

\begin{abstract}
Tall Buildings are highly susceptible to wind induced lateral loads and is required to be designed with greater accuracy. The codal provision IS 875 (part 3) which is usually used, has a limitation that the coefficient of pressure $C_{p}$ values available are, only for 0 and 90 degrees wind incidence angles and for standard cross sections of buildings only. Therefore wind tunnel experiments are carried out to measure wind loads which provide reliable results than the code. This Paper deals with, computational fluid dynamics, an alternative and highly dependable tool to predict the wind related phenomena on buildings. A numerical evaluation of wind pressure is done for the different cases of buildings in IS 875 part-3. Wind load obtained by using IS 875 part-3 are compared with the result obtained from CFD in ANSYS Fluent $\mathbf{1 5 . 0}$ and results are found to be in good agreement .The mean area weighted average values of Coefficient of pressure are also computed for various wind incidence angle.

Keywords: Computational Fluid Dynamics, Wind load, Coefficient of Pressure and ANSYS Fluent
\end{abstract}

\section{INTRODUCTION}

The world is experiencing a population growth and this leads to more demand for human facilities. To design a civil engineering structure three main requirements need to be considered: durability or long service life, serviceability, and human safety. The construction of structures with respect to the above criteria requires a proper investigation of wind induced load on structures. Tall buildings, long span, cable-stayed and suspension bridges because of their height, shape and weight are more vulnerable to wind load. Henceforth the major concern for designers is to ensure the stability of these structures.

In the past, wind tunnel tests were used by engineers to understand the response of bridge to wind load and assess their design. However, these experiments are time and cost consuming; Upto 6 to 8 weeks are needed to perform a typical wind tunnel test. The development of computer technology in recent years has led to the trend of computer modelling and analysis to design tall structures. A plenty of numerical methods based on computational fluid dynamics (CFD) has been developed to conduct wind analysis on bridges and buildings.

\section{ANALYSIS USING ANSYS CFD}

CFD is the analysis of the system involving fluid flow, heat transfer and associated phenomena such as chemical reactions by means of computer based simulations. In this we use the Finite Volume Method for calculating the unknowns such as pressure, velocity, etc. They can be used as a design tool in several industrial applications such as

1. Automobile and Engine.

2. Civil Engineering.

3. Environmental Engineering.

4. Manufacturing.

5. Naval Architecture.

6. Medical Physics

\section{A. Numerical Model and Domain}

The geometrical modelling for the numerical simulation of CAARC building model mimics the 1:400 scale models. The CAARC model has a rectangular prismatic shape with dimensions $100 \mathrm{ft}\left(\mathrm{D}_{\mathrm{x}}\right)$ by $200 \mathrm{ft}\left(\mathrm{D}_{\mathrm{y}}\right)$ by $600 \mathrm{ft}(\mathrm{H})$ height. The flow is described in a Cartesian coordinate system(x, $y$, $z$ ), in which the $x$-axis is aligned with the steam-wise direction, $\mathrm{z}$-axis is in the perpendicular direction and the $\mathrm{y}$ axis is in the vertical direction. The details of computational domain and building model are given in Fig. 1.

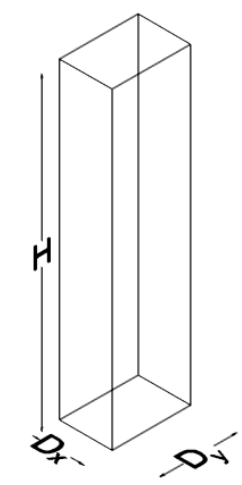

Fig. 1 Numerical model used for study

\section{B. Meshing}

Meshing the structure is very important since the values of output may vary when we are using unstructured mesh. Also very fine mesh leads to time lag. Hence optimum mesh should be chosen by calculating the $y$ plus value for the boundary of the building. Here the building model is 
meshed by using the multizone method. By using this method we can get the structured mesh around the domain and the model.

The face of the building wall is divided into 5 parts along the $\mathrm{y}$ and $\mathrm{x}$-axis. Along the $\mathrm{z}$-axis the building wall is divided into 10 parts inorder to get the optimum value of Coefficient of pressure around the building wall. Also around the building wall the domain is split up into many parts and then biasing is done in order to get the results nearer to codal value. The overall nodes and elements are 59K and 54K respectively. Fig. 2 and Fig. 3represent the 2D elevationand plan meshing of domain and model respectively.

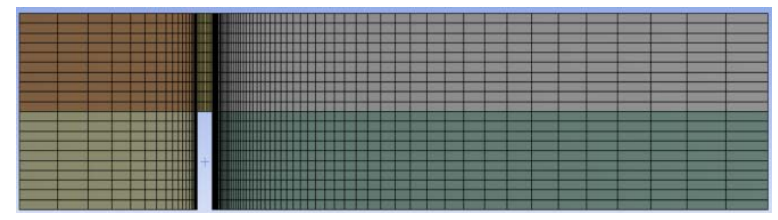

Fig. 2 2D Meshing of Numerical model and Domain (Elevation)

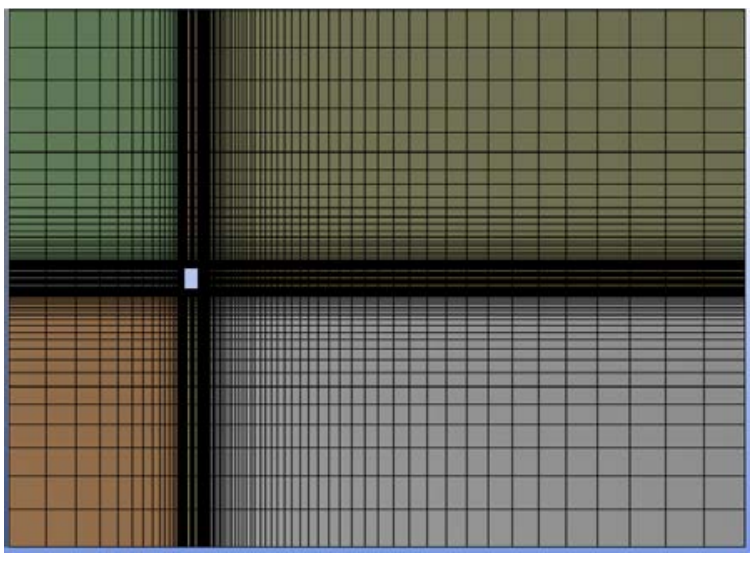

Fig. 3 2D Meshing of Numerical model and Domain (Plan)

\section{Setting up Physical Environment}

For most engineering studies, it is unnecessary to resolve the details of turbulent fluctuations. CFD engineers are almost always satisfied with the information about the timeaveraged properties of the flow of a fluid such as pressures,velocities, stresses, etc. the majority of turbulent computations are carried out based on the procedure presented on the RANS equation. The most common models used for RANS flow equation

1. Zero equations (e.g. Mixing length model)

2. One equation (e.g. Spalart-Allmaras model)

3. Two equation (e.g. k-epsilon model and k-omega model)

4. Seven equation (e.g. Reynolds stress model)

The two-equation turbulence model allows the determination of both, a turbulent length and time scale by solving two separate transport equations. In this study
Oneequation turbulence model viz. Spalart-Allmaras model is used. The boundary conditions for the walls of the domain and building is shown in Fig. 4.

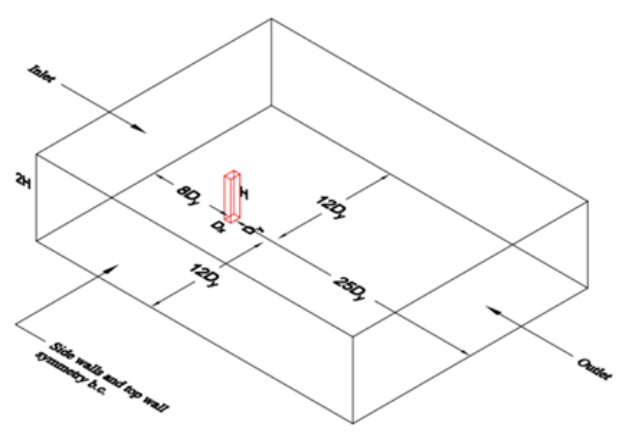

Fig. 4 Computational domain and Boundary condition

\section{Inlet Velocity}

The boundary condition for the inlet velocity is given as user defined function. By means of user defined function we can produce the atmospheric boundary condition inside the domain.At heights of approximately $1200 \mathrm{ft}$. (366 m) above ground, the wind speed is virtually unaffected by surface friction, and its movement is solely dependent on prevailing seasonal and local wind effects.A retarding effect occurs in the wind layers near the ground, and these inner layers in turn successively slow the outer layers. The height at which velocity ceases to increase is called the gradient height, and the corresponding velocity, the gradient velocity.The height through which the wind speed is affected by topography is called the atmospheric boundary layer. The wind speed profile within this layer is given by power law with coefficient equal to 0.16 . The mathematical equation is given by

$$
V_{z}=\left(\frac{Z}{Z_{g}}\right)^{1 / \alpha} V_{g}
$$

Where

$\mathrm{V}_{\mathrm{z}}$-Velocity at height $\mathrm{z}$ in $\mathrm{m} / \mathrm{s}$

$\mathrm{V}_{\mathrm{g}}$ - Reference velocity in $\mathrm{m} / \mathrm{s}$

$\mathrm{Z}$ - Height in $\mathrm{m}$

$\mathrm{Z}_{\mathrm{g}}$ - Reference height in $\mathrm{m}$

$\alpha$ - Power law Coefficient

The reference height is taken as the domain height and the reference velocity is chosen based on the Reynolds number $1 \times 10^{5}$. The velocity profile used for the study is shown in Fig. 5.

\section{E. User Defined Function in C-Program}

C allows you to define functions according to your need. These functions are known as user-defined functions. Here the inlet velocity is given by means of UDF only. Power 
law equation is incorporated in C-program to solve for velocity
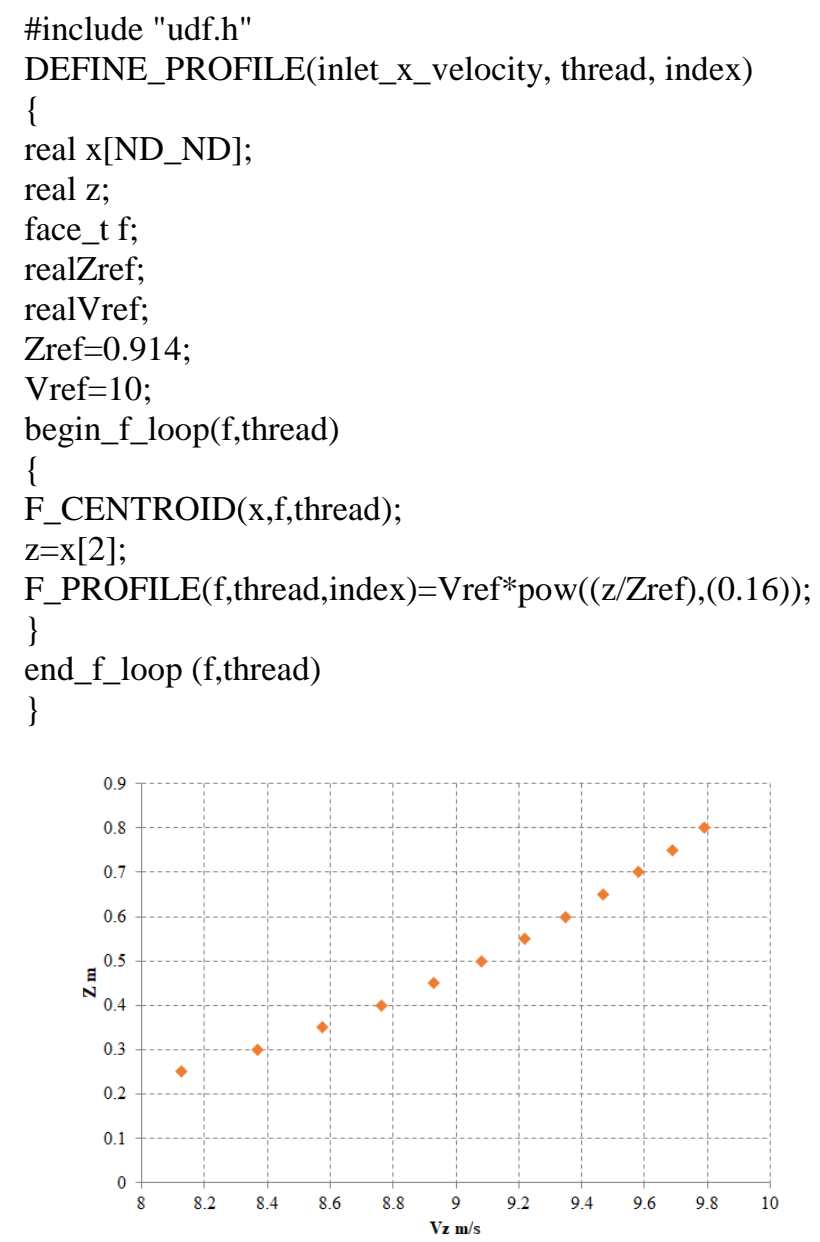

Fig. 5 Velocity profile used for study

\section{RESULTS AND DISCUSSION}

The values of Cp obtained from the ANSYS Fluent 15.0 matches well with the values in IS: 875 (Part 3) Table 1. From the table 1 it is clear that the sidewalls and leeward face of the building obtained from CFD varies slightly from the code. The values are done for $0^{\circ}$ incidence in Table 1 . The faces of the building wall named as shown in Fig. 6. Face A represents the windward side of building, Face B and $\mathrm{D}$ represents the side wall of building and Face $\mathrm{C}$ represents the leeward side of building.

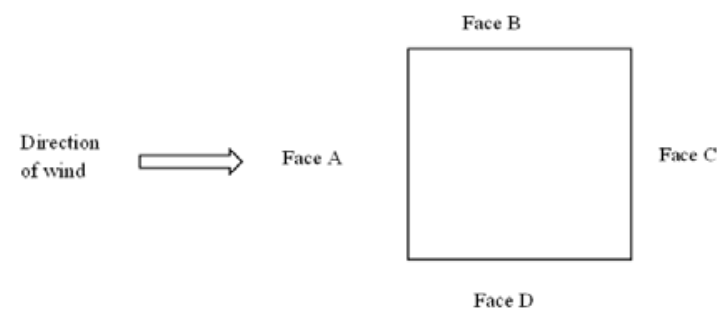

Fig. 6 Names of Different faces of the building
TABLE I CP VALUES FROM CFD AND IS: 875 (PART 3)

\begin{tabular}{|l|c|c|c|c|c|c|}
\hline \multirow{2}{*}{ Method } & \multirow{2}{*}{$\begin{array}{c}\text { Building } \\
\text { height } \\
\end{array}$} & \multirow{2}{*}{$\begin{array}{c}\text { Building } \\
\text { plan } \\
\text { ratio }\end{array}$} & $\begin{array}{c}\text { Face } \\
\text { A }\end{array}$ & $\begin{array}{c}\text { Face } \\
\text { B }\end{array}$ & $\begin{array}{c}\text { Face } \\
\text { C }\end{array}$ & $\begin{array}{c}\text { Face } \\
\text { D }\end{array}$ \\
\cline { 4 - 7 } $\begin{array}{l}\text { IS } 875 \\
\text { (Part 3) }\end{array}$ & $\frac{\mathrm{h}}{w}>\infty$ & $\frac{l}{w}=2$ & 0.85 & -0.75 & -0.75 & -0.75 \\
\hline CFD & $\frac{H}{D_{x}}=6$ & $\frac{D_{y}}{D_{x}}=2$ & 0.88 & -0.85 & -0.66 & -0.85 \\
\hline
\end{tabular}

Since the values obtained from CFD appears to be promising the same procedure is done for obtaining the various $C_{p}$ values for different angle of wind. For the various angle of incidence the $C_{p}$ values are computed are tabulated as below in Table 2. From the table it is clear that the $C_{p}$ values are critical for $0^{\circ}$ incidence wind for rectangular structures. Also the wind angle for $90^{\circ}$ matches well with the IS: 875 (Part 3).

TABLE 2 CP VALUES FOR DIFFERENT ANGLE OF ATTACK

\begin{tabular}{|c|c|c|c|c|}
\hline Wind Angle & Face A & Face B & Face C & Face D \\
\hline 0 & 0.88 & -0.85 & -0.66 & -0.85 \\
\hline 10 & 0.71 & -0.72 & -0.55 & -0.72 \\
\hline 20 & 0.52 & -0.58 & -0.43 & -0.58 \\
\hline 30 & 0.36 & -0.38 & -0.29 & -0.38 \\
\hline 90 & -0.7 & -0.83 & 0.8 & -0.83 \\
\hline
\end{tabular}

\section{CONCLUSION}

From the study carried out the following broad conclusions are arrived. Computational Fluid Dynamics (CFD) is a suitable alternative to predict the wind related phenomena on buildings and other structures. $\mathrm{C}_{\mathrm{p}}$ values obtained from the present simulation using ANSYS Fluent matches well with the IS 875 (Part 3). The Coefficient of pressure for various shapes of the building which are not included in IS 875 part-3 can be found by assuming suitable physical environment and solving using CFD. Similarly the various other parameters pressure and velocity contours can be obtained by using CFD post processing.

\section{REFERENCES}

[1] Twinsy P. Modiand AtulK. Desai, "Wind Effects on Tall Buildings Having Skip Floor Using Computational Fluid Dynamics", in Proc. SARC International Conference, New Delhi, India, Mar.26, 2017, ISBN: 978-93-86291-639.

[2] A. K. Mittal, "Wind flow simulation in the vincity of tall buildings through CFD”, in Proc. APCWE-VIII, Chennai, India, pp. 682-690, Dec.10-14, 2013.

[3] Agerneh K. Dagnew and Girma T. Bitsuamlak, "Computational evaluation of wind load on buildings”,Wind and Structures, Vol. 16, No. 6, pp. 629-660, June 2013.

[4] Indian Standard for Code of practice for design loads for buildings and structures, IS 875 part 3-1987.

[5] Fluent 14.5, User's Guide (ANSYS Fluent Inc, Lebonan, USA) 2013.

[6] Bilal assaad, "Wind effect on Super Tall Buildings using CFD and Structural Dynamics”, M.S. thesis, Dept. of Civil Engg., Florida AtlanticUniv.,Florida, 2015. 